\title{
Perioperative Blood loss in Open Retropubic Radical ProstaTECTOMY - Is it SAFe to Get Operated at an Educational Hospital?
}

\author{
A. Karl, A. Buchner, H. Becker, M. Staehler, M. Seitz, C. Stief
}

Department of Urology, University of Munich-Campus Grosshadern, Munich, Germany

\begin{abstract}
Introduction: Blood loss during radical prostatectomy has been a long term issue. The aim of this study was to investigate the influence of the training level of the first assistant regarding blood loss in open retropubic radical prostatectomy at an educational hospital.

Material and Methods: 364 patients underwent radical prostatectomy from $11 / 2006$ to $10 / 2007$ at one institution operated by one surgeon. In 319 patients all predefined parameters were obtained. Training level was determined by year of residency (1-5yrs) or consultant status. Perioperative blood loss was calculated using three parameters: Hemoglobin level before and after surgery, postoperative sucker volume and weight of compresses. Furthermore the influence of prostatic size and BMI was analyzed.

Results: The Hb-decrease $24 \mathrm{~h}$ postoperatively was $2.4 \mathrm{~g} / \mathrm{dl}$ median $(-0.4-7.6 \mathrm{~g} / \mathrm{dl})$; sucker volume was 250 $\mathrm{ml}$ median $(10-1500 \mathrm{ml})$; weight of compresses and swabs was $412 \mathrm{~g}$ median $(0-972 \mathrm{~g})$. One patient needed a transfusion with two erythrocyte concentrates one day after the surgery. There was no significant correlation regarding $\mathrm{Hb}$-decrease $(\mathrm{p}=0.86)$ or sucker volume plus weight of compresses $(p=0.59)$ in regard to the years of residency of the assisting physician. Also the number of assisted operations $(n=<$ or $>20)$ had no significant influence on calculated blood loss $(p=0.38)$. Conclusions: For an experienced surgeon the impact of the assistant regarding blood loss seems negligible. The training level of the assistant was not significantly correlated to a rise or decrease of perioperative blood loss. In our data radical prostatectomy could be safely performed at an educational hospital independent of the training level of the first assistant.
\end{abstract}

Key words: blood loss, educational hospital, training level, radical prostatectomy

\section{INTRODUCTION}

Blood loss during radical prostatectomy has been a long term issue. New techniques and advanced experience made radical prostatectomy a safe procedure with a well defined risk for patients.

Blood loss during an open retropubic, laparoscopic or robotic assisted radical prostatectomy varies depending on the performing centre and the technique used. Current data show blood loss after retropubic surgery ranging from 600 to $1,500 \mathrm{ml}$ mean [1-7] vs. 220 to $1,100 \mathrm{ml}$ mean after laparoscopic approach [8$12]$.

Different factors, like body mass index, prostatic volume, and pelvic size have been described to potentially influence blood loss during radical prostatectomy. [13; 14]

To estimate a possible impact of the first assistant on the perioperative blood loss, three parameters were analysed in this study: hemoglobin level before the surgery and $24 \mathrm{~h}$ after the surgery, sucker volume after the surgery, and weight of all used compresses and swaps after the surgery. To avoid possible bias all operations were performed by the same surgeon in less than one year of observation.

\section{MATERIAL AND Methods}

We analysed prospectively the data of 364 prostate cancer patients who were consecutively admitted to our hospital for open radical prostatectomy. All patients were operated on between November 2006 and October 2007 by one surgeon. Of 364 patients, 319 could be evaluated according to all three predefined parameters. Every operation was performed in a one assistant setting. The training level of the assisting physician ranged from first year residency up to the status of a well experienced consultant. In most cases bilateral pelvic lymphadenectomy was performed. The assistant performed the lymphadenectomy unilaterally under the guidance of the surgeon. Lymphadenctomy was performed mainly as the so called standard variant, including lymph nodes in the obturator fossa and the external iliac artery. Perioperative blood loss was calculated defining three parameters.

\section{Hemoglobin level $(\mathrm{Hb}, \mathrm{g} / \mathrm{dl})$ :}

Routine blood parameters were obtained including haemoglobin $(\mathrm{g} / \mathrm{dl})$ on the day of patients' admittance to the hospital. The normal range of $\mathrm{Hb}$ level for men was 14 to $18 \mathrm{~g} / \mathrm{dl}$ according to our laboratory. All routine blood parameters were determined a second time $24 \mathrm{~h}$ after the surgery. Based on the results the postoperative $\mathrm{Hb}$ decrease was calculated. $\mathrm{Hb}$ level was determined a third time after (5-8 days after surgery) in 244 of $319(76 \%)$ of cases. 


\section{Sucker volume (ml):}

The sucker volume was determined after the operation (10 $\mathrm{ml} \mathrm{scale)}$.

\section{Weight of used compresses and swabs (g):}

All used compresses and swabs were weighed before and after the surgery. The predetermined own weight was subtracted by the final weight after surgery. Of the total weight, the amount of the used irrigation fluid $(100 \mathrm{ml}=100 \mathrm{~g})$, the calculated urine production during the time of an opened urethra (average of 20 Patients, $50 \mathrm{ml}=50 \mathrm{~g}$ ) and the urinary catheter balloon block volume $(15 \mathrm{ml}=15 \mathrm{~g})$ were subtracted.

All procedures were performed as open retropubic radical prostatectomy. Assisting doctors were enrolled in their first, second, third, forth or fifth year of residency or as consultants, 3, 2, 3, 3, 2, 10 in number, respectively. The change of year of residency during the observation time was respected in the final evaluation. Body mass index and prostatic size (determined by transrectal ultrasound) were assessed at the time of patients' admittance to the hospital.
The first aim of this study was to determine a possible correlation between the training level of the assisting doctor and the calculated perioperative blood loss. Furthermore the influence of prostatic size and BMI on the estimated perioperative blood loss was analysed.

\section{RESULTS}

On the first postoperative day the decrease of the haemoglobin level was $2.4 \mathrm{~g} / \mathrm{dl}$ median for all cases ($0.4-7.6 \mathrm{~g} / \mathrm{dl}$ ). The average sucker volume was $250 \mathrm{ml}$ median $(10-1500 \mathrm{ml})$. The weight of compresses and swabs was $412 \mathrm{~g}$ median $(0$ - $972 \mathrm{~g}$ ), calculated as described above. Sucker volume and weight parameter were combined for analysis.

There was detected no significant correlation between the level of $\mathrm{Hb}$-decrease and the training level of the assistant ( $p=0.86$, see Fig. 1$)$. Also no significant change in Hb-value $24 \mathrm{~h}$ after surgery and 5-8 days after surgery was detected. There was detected no significant correlation between sucker volume plus weight of compresses and the training level of the assistant either ( $p=0.59$, see Fig. 2$)$. All obtained para-
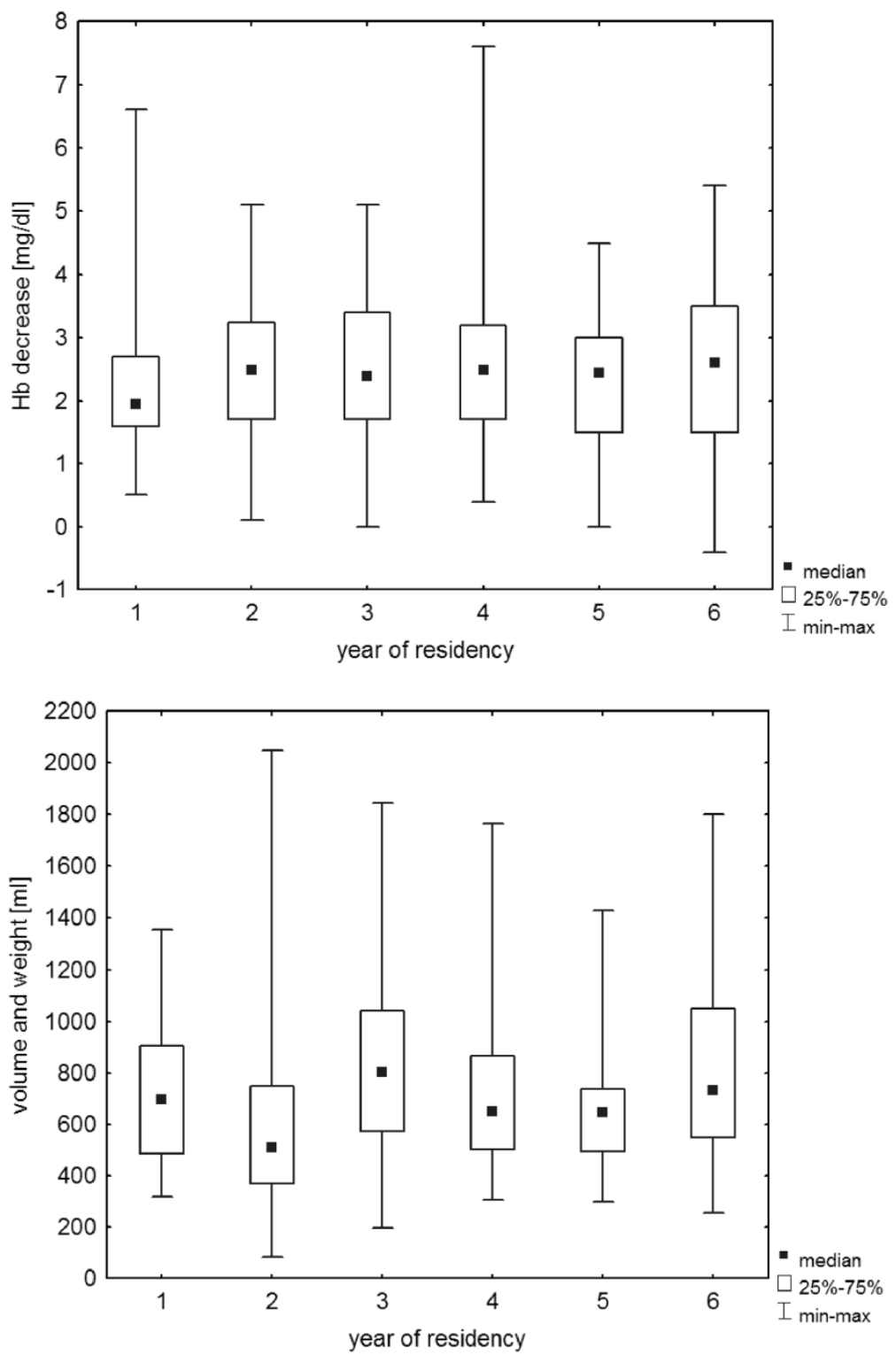

Fig. 1. Hb-decrease $(\mathrm{g} / \mathrm{dl})$ in relation to the training level of the first assistant $\mathrm{p}=0.86(1-5$ years of residency, $6=$ consultant status).
Fig. 2. Sucker volume + weight of compresses in relation to the training level of the first assistant $\mathrm{p}=0.59(1-5$ years of residency, $6=$ consultant status). 
Table 1. Parameters.

\begin{tabular}{|c|c|c|c|c|c|}
\hline 1. year of residency & average & median & minimum & maximum & standard dev. \\
\hline Hb-Decrease $(\mathrm{g} / \mathrm{dl})$ & 2.23 & 1.95 & 0.5 & 6.6 & 1.16 \\
\hline Suckervol. + weight of compresses (g) & 717.61 & 698 & 318 & 1354 & 272.35 \\
\hline 2. year of residency & average & median & minimum & maximum & standard dev. \\
\hline Hb-Decrease (g/dl) & 2.57 & 2.5 & 0.1 & 5.1 & 1.19 \\
\hline Suckervol. + weight of compresses (g) & 595.24 & 511 & 84 & 2048 & 338.78 \\
\hline 3. year of residency & average & median & minimum & maximum & standard dev. \\
\hline Hb-Decrease (g/dl) & 2.58 & 2.4 & 0 & 5.1 & 1.12 \\
\hline Suckervol. + weight of compresses (g) & 833.7571 & 803 & 196 & 1846 & 353.34 \\
\hline 4. year of residency & average & median & minimum & maximum & standard dev. \\
\hline Hb-Decrease (g/dl) & 2.58 & 2.5 & 0.4 & 7.6 & 1.28 \\
\hline Suckervol. + weight of compresses (g) & 730.76 & 649 & 306 & 1764 & 329.31 \\
\hline 5.year of residency & average & median & minimum & maximum & standard dev. \\
\hline Hb-Decrease $(\mathrm{g} / \mathrm{dl})$ & 2.27 & 2.45 & 0 & 4.5 & 1.14 \\
\hline Suckervol. + weight of compresses (g) & 681.86 & 645 & 298 & 1430 & 314.97 \\
\hline $6=$ Consultant status & average & median & minimum & maximum & standard dev. \\
\hline Hb-Decrease $(\mathrm{g} / \mathrm{dl})$ & 2.49 & 2.6 & -0.4 & 5.4 & 1.26 \\
\hline Suckervol. + weight of compresses (g) & 823.42 & 732 & 256 & 1799 & 378.36 \\
\hline
\end{tabular}

Table 2. Correlation between perioperative blood loss with BMI and prostatic volume.

\begin{tabular}{|c|c|c|c|}
\hline & mean & median & range \\
\hline Body mass index (BMI) & 26.6 & 26.1 & $18.5-40.8$ \\
\hline Prostatic volume (ccm3) & 42.6 & 39.0 & $10-150$ \\
\hline Perioperative blood loss correlated with BMI & $\mathrm{p}=0.32$ & & \\
\hline Perioperative blood loss correlated with prostatic volume & $\mathrm{p}=0.26$ & & \\
\hline
\end{tabular}

meters according to each year of residency are presented in Table 1.

There was no significant difference between 1-3 years vs. $>3$ years of residency in regard to sucker volume plus weight of compresses $(p=0.59)$. There was detected no significant difference regarding $\mathrm{Hb}$ decrease $(p=0.22)$ or sucker volume plus weight of compresses $(p=0.38)$ for physicians with more respectively less than 20 assisted radical prostatectomies.

There has been detected no statistical significant correlation between perioperative blood loss and body mass index $(p=0.32)$ or prostatic size $(p=0.2)$ (see Table 2). One patient needed a transfusion of two erythrocyte concentrates one day after the surgery. For statistical analysis the Mann-Whitney-U test and Kruskal Wallis analysis were performed.

\section{DISCUSSION}

Blood loss during radical prostatectomy has been a long term issue. This observation is supported by current literature, which highlights a series of studies comparing different surgical techniques regarding complications and blood loss. [1-5; 7-12; 15] Different factors as cause for an increased perioperative blood loss have been studied so far. Patients' body mass in- dex $[14 ; 16 ; 17]$, prostate size [14; 18], pelvic size [13] etc. have been study targets.

In our study we investigated for the first time the influence of the training level of the first assistant on the perioperative blood loss in open radical prostatectomies. The hypothesis for this study was that especially in a demanding operation like open radical prostatectomy the assistance by a relatively inexperienced physician could be related to a higher level of perioperative blood loss. This is a common concern of patients who get operated at an educational hospital. Inexperience of the assistant in surgery in general or misinterpretation of a critical situation could represent the cause for initial bleeding or could prolong actual bleeding time during surgery. This question seems to be important especially at an educational hospital where a large number of physicians start their surgical training. This study was initiated to control optimum surgical care and to assess data for patients' information according this issue.

To analyze the influence of the assisting physician only, all evaluated operations were performed by one surgeon in less than one year of observation time avoiding bias of different surgeons or a possible technique change over time.

The obtained data show that perioperative blood loss in open radical prostatectomy, calculated by the 
use of three different parameters, is not statistically significantly correlated with the training level of the assistant. The study was designed to estimate perioperative blood loss most accurately. Concerning the parameter $\mathrm{Hb}$-decrease the question was raised, whether a single postoperative $\mathrm{Hb}$-measurement was sufficient to base further conclusions on. Therefore the Hb-level was determined one more time five to eight days after surgery in $76 \%$ of cases and correlated with the $24 \mathrm{~h}$ value. No significant difference between the two levels was detected, so the $24 \mathrm{~h}$ value was used for all calculations. To determine perioperative blood loss most accurately, details like perioperative urine production, amount of irrigation fluid and catheter balloon block volume were obtained and respected in the final calculation.

Analyzing the dataset, there were no significant differences in the readings when the experience of the assisting doctor varied. Therefore perioperative blood loss seems to be dependent mainly on the surgeon himself, as she/he is the person who prevents or controls major bleeding. The assistant influences perioperative blood loss presumably only by making a substantial mistake such as hurting a major blood vessel during LAE or by slowing down the treatment of an acute bleeding through inappropriate reactions. Both conditions were not observed or rather had no statistically significance in the presented dataset.

Interestingly the presented data also demonstrate that even a high training level of the assisting physician is not correlated with a decrease of perioperative blood loss. This supports further the theory that is mainly the surgeon her/himself, who is responsible for perioperative blood loss.

In the literature there is a current debate about the influence of BMI on perioperative complications including blood loss in retropubic prostatectomy [14; 16 ; 17]. Chang et al. demonstrated in their trial that BMI was a significant correlative predictor of estimated blood loss on multivariate analysis.[16] On the other hand Singh et al. could not find a significant impact of BMI on operative or postoperative morbidity including blood loss. [14] In our data set there was found no impact of BMI on perioperative blood loss $(p=0.32)$. However it has to be mentioned that the number of obese patients (BMI greater 29) was rather low in our cohort. (BMI mean 26.6)

Also prostatic volume is reported to be one of the factors that may negatively influence perioperative blood loss. Singh et al could show in their study that a prostate volume higher than $50 \mathrm{ccm} 3$ correlated with higher blood loss but did not reach statistical significance [14]. The size of the prostate seems to play a more important role in the use of laparoscopic or robotic assisted operations as shown by Bozco et al. [19]. In our dataset there was found no statistically significant correlation between prostatic size and perioperative blood loss $(\mathrm{p}=0.26)$

A limitation of this study is that only perioperative blood loss was calculated, and no drainage-volume of the postoperative phase was recorded.

It would be of interest whether these observations are transferable to other centres, using different techniques like laparoscopy or robotic assisted surgery.
All in all the presented data show that the impact of the assistant regarding blood loss seems negligible. This important information can be used to better inform patients who undergo radical prostatectomy especially regarding the question of perioperative safety at an educational hospital.

\section{CONCLUSION}

For an experienced surgeon using modern surgical techniques the impact of the assistant regarding blood loss seems negligible. The training level of the assistant seems not to be correlated to a rise or decrease of perioperative blood loss. In our data radical retropubic prostatectomy could be safely performed at an educational hospital independent of the training level of the first assistant.

\section{REFERENCES}

1. Arai Y, Egawa S, Tobisu K et al (2002) Radical retropubic prostatectomy: time trends, morbidity and mortality in Japan. BJU Int 85(3):287-294

2. Augustin H, Hammerer P, Graefen $M$ et al (2003) Intraoperative and perioperative morbidity of contemporary radical retropubic prostatectomy in a consecutive series of 1243 patients: results of a single center between 1999 and 2002. Eur Urol 43(2):113-118

3. Catalona W, Carvalhal G, Mager D et al (1999) Potency, continence and complication rates in 1,870 consecutive radical retropubic prostatectomies. J Urol 162(2):433-438

4. Lepor H, Nieder A, Ferrandino M (2001) Intraoperative and postoperative complications of radical retropubic prostatectomy in a consecutive series of 1,000 cases. J Urol 166(5):1729-1733

5. Romero-Otero J, Touijer K, Guillonneau B (2007) Laparoscopic radical prostatectomy: contemporary comparison with open surgery. Urol Oncol 25(6):499-504

6. Touijer K, Eastham J, Secin F et al (2008) Comprehensive prospective comparative analysis of outcomes between open and laparoscopic radical prostatectomy conducted in 2003 to 2005. J Urol 179(5):1811-1817

7. Zincke H, Bergstralh E, Blute M et al (1994) Radical prostatectomy for clinically localized prostate cancer: long-term results of 1,143 patients from a single institution. J Clin Oncol. 12(11):2254-2263

8. Eden C, Cahill D, Vass J et al (2002) Laparoscopic radical prostatectomy: the initial UK series. BJU Int 90(9):876882

9. Guillonneau B, Cathelineau X, Doublet J et al (2002) Laparoscopic radical prostatectomy: assessment after 550 procedures. Crit Rev Oncol Hematol 43(2):123-133

10. Rassweiler J, Seemann O, Schulze M et al (2003) Laparoscopic versus open radical prostatectomy: a comparative study at a single institution. J Urol169(5):1689-1693

11. Rozet F, Galiano M, Cathelineau X et al (2005) Extraperitoneal laparoscopic radical prostatectomy: a prospective evaluation of 600 cases. J Urol 174(3):908-911

12. Stolzenburg J, Rabenalt R, Do M et al (2005) Endoscopic extraperitoneal radical prostatectomy: oncological and functional results after 700 procedures. J Urol 174:12711275

13. Sekita N, Egoshi K, Mikami K (2007) Predicting blood loss during radical prostatectomy using internal pelvimetry. Hinyokika Kiyo 53(1):19-23

14. Singh A, Fagin R, Shah G et al (2005) Impact of prostate size and body mass index on perioperative morbidity after laparoscopic radical prostatectomy. J Urol 173(2):552-554 
15. Rassweiler J, Stolzenburg J, Sulser T et al (2006) Laparoscopic radical prostatectomy-the experience of the German Laparoscopic Working Group. Eur Urol 49(1):113119

16. Chang I, Byun S, Hong S et al (2007) Assessing the body mass index of patients might help to predict blood loss during radical retropubic prostatectomy in Korean men. BJU Int 99(3):570-574

17. Chang S, Duong D, Wells N et al (2004) Predicting blood loss and transfusion requirements during radical prostatectomy: the significant negative impact of increasing body mass index. J Urol 171(5):1861-1865

18. Meraj S, Nagler H, Homel P et al (2003) Radical prostatectomy: size of the prostate gland and its relationship with acute perioperative complications. Can J Urol 10(1):17431748

19. Boczko J, Erturk E, Golijanin D et al (2007) Impact of prostate size in robot-assisted radical prostatectomy. J Endourol 21(2):184-188
Received: April 16, 2009 / Accepted: May 5, 2009

Address for correspondence:

Alexander Karl, MD

Department of Urology

University of Munich-Campus Grosshadern

Marchioninistr. 15

81377 Munich, Germany

Tel.: $\quad+4989 / 7095-0$

Fax.: $\quad+4989 / 7095-8890$

E-mail: alexander.karl@med.uni-muenchen.de 